\title{
A Compact Broadband Antenna for Wireless Terminals in Telemetry and Communication Systems
}

\author{
Gaojian Kang ${ }^{1}$, Feng Wang ${ }^{1}$, Yuanyuan Tian ${ }^{1}$, Yanlei Ji ${ }^{2}$ \\ ${ }^{1}$ Beijing Institute of Astronautical Systems Engineering, Beijing, China,
}

Gjkang.bj@gmail.com

${ }^{2}$ No.23 Research Institute, China Electronics Technology Group Corporation, Shanghai,China

\begin{abstract}
:
A compact broadband antenna with a parasitic radiating strip, which could meet the demand for high data rate and high capacity, is proposed. By adding parasitic strip into an antenna, an additional electromagnetic resonant mode is introduced and further the bandwidth of the antenna is broadened. The parasitic strip adopts meandered-line structure to reduce occupying area. The measured $-10 \mathrm{~dB}$ impedance bandwidth is $1080 \mathrm{MHz}(1920-3000 \mathrm{MHz})$, covering the UMTS, WLAN and WiMAX bands in modern wireless communication system and the frequency band used in telemetry system.
\end{abstract}

Key words: broadband, parasitic strip, telemetry, telecommunication, compact.

\section{Introduction}

There is an essential requirement for the wireless terminals with low profile and the function of multi-system operations with the rapid development in wireless communications. The antennas, as the key transceiving components of the wireless terminals, are required to be with compact size and multi-band functionality. Various techniques have been adopted to broaden the antenna bandwidth, e.g., capacitive loading, capacitive feed, adding parasitic shorted strip or patch, use of slots [14]. The method of adding parasitic branch or strip into an antenna is often used by the antenna designers because it can generate additional resonant modes and further broaden the bandwidth. An internal planar inverted-F antenna (PIFA) combining shorted parasitic patches to achieve multiband operation was proposed in [4] and it could cover the GSM, DCS, PCS, UMTS, HIPERLAN/2 and IEEE 802.11a bands for 2.5:1 VSWR standard. Reference [5] presented a low-profile planar monopole antenna with a shorted parasitic inverted-L wire for WLAN applications. The driven monopole element and shorted parasitic wire can separately control the operating frequencies of two excited resonant modes. In order to further make the antenna compact and simultaneously cover the following communication standards: UMTS, WiBro, WLAN, WiMAX and telemetry frequency bands, a monopole antenna with low profile is required.

In this paper, a compact dual-frequency monopole antenna with a parasitic strip is proposed. By introducing a parasitic radiating strip into the antenna, a new resonant mode is generated and thus, the bandwidth of the proposed antenna is effectively enlarged.The antenna, printed on the upper-board and sideboard, is vertically placed at the upper-left corner of the main-board in the horizontal plane. The antenna part occupies less area of the main-board and is very suitable for wireless terminals. 


\section{Antenna design}

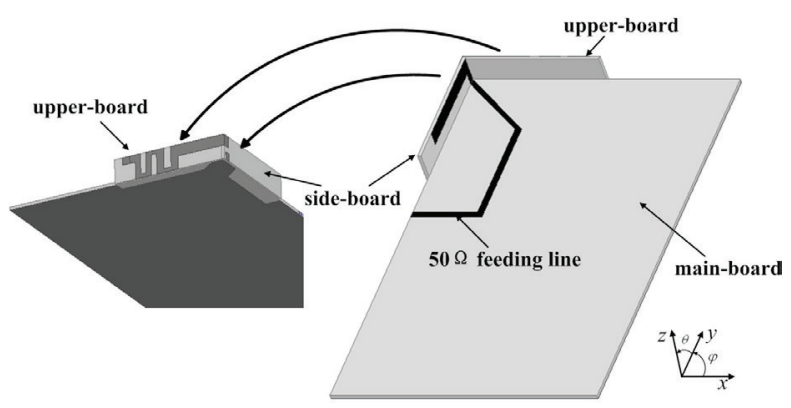

Fig. 1. Geometry of the proposed antenna.

The overall geometry of the antenna is illustrated in Figure1. As shown in Figure1, the antenna system adopts 3-D structures, which comprise three boards, i.e. a horizontal mainboard, a vertical upper-board and a vertical side-board, and thus occupies less area of the main-board. The main-board has dimensions of $95 \mathrm{~mm} \times 60 \mathrm{~mm}$, and the side-board and upperboard have dimensions of $30 \mathrm{~mm} \times 6.5 \mathrm{~mm}, 30$ $\mathrm{mm} \times 6.5 \mathrm{~mm}$, respectively. All of them are FR4 substrate boards with a thickness of $0.8 \mathrm{~mm}$ and a relative permittivity of 4.4 . The proposed antenna consists of a monopole antenna (a-b-c) and a meandered parasitic strip (c'-d'-e'). As shown in Figure2 (a) 、 (b) and (d), the monopole antenna $(a-b-c)$ is printed on the top layer of the side-board and connected to the feeding line at Position $a$. In order to broaden the bandwidth, the meandered parasitic strip (c'-d'-e') is introduced to generate an additional resonant mode, as shown in Figure2 (a) and (c). The parasitic strip (c'-d'-e') is composed of two sections, $c^{\prime}-d$ ' section and d'-e' section. The $c$ '-d' section is printed on the bottom layer of the side-board, while the d'-e' section is printed on the bottom layer of the upper-board; these two sections conjugate at Position $d$ '. The meandered structure adopted by the parasitic strip (c'-d'-e') can adjust the impedance matching at the operating bandwidth as well as effectively reduce the occupying area of the parasitic strip. The a'-b' section is printed on the bottom layer of the side-board and connected to the metal ground plane at Position a', as shown in Figure2 (a)、(c) and (e). It can be seen in Figure 2 (b) and (c) that, the $50 \Omega$ microstrip feeding line is printed on the top layer of the main-board.

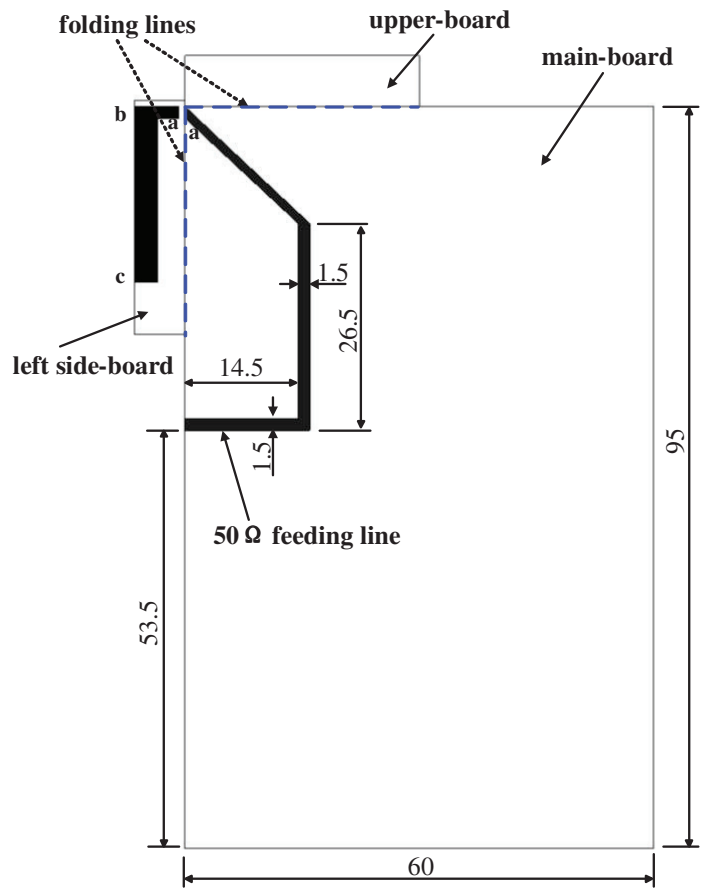

(a)

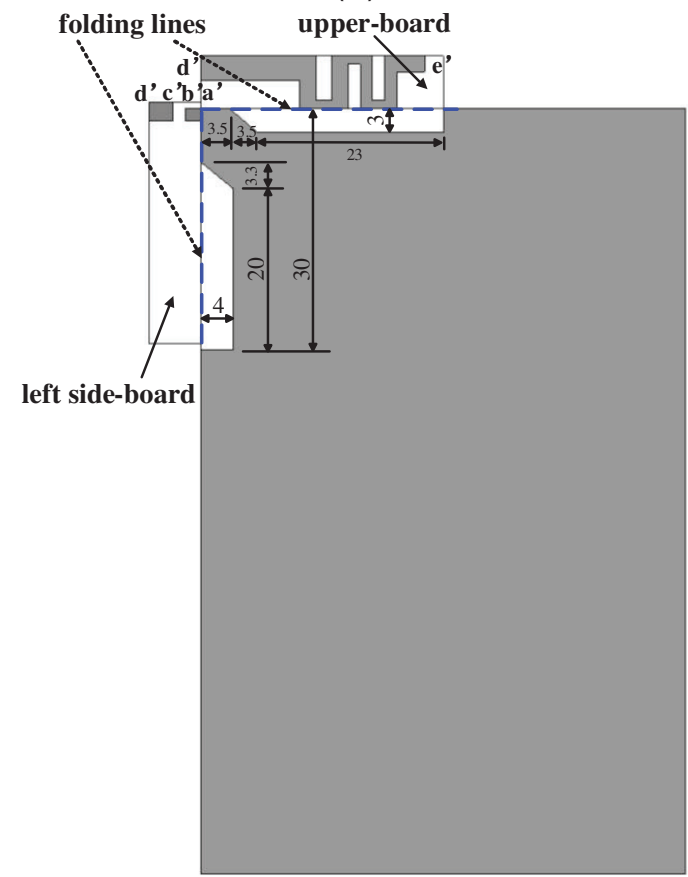

(b)

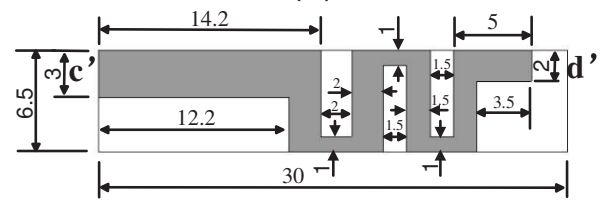

(c)

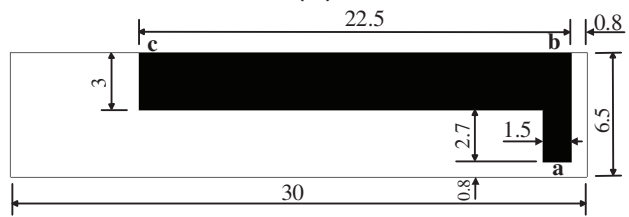

(d) 


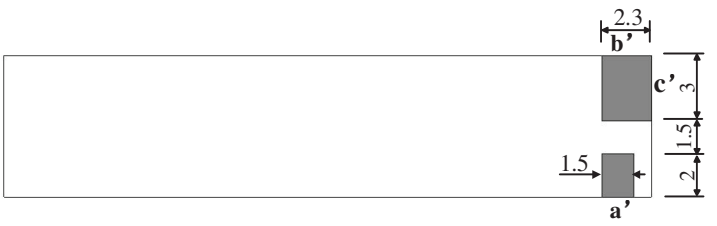

(e)

Fig. 2. Dimensions of the proposed antenna in millimeters (the top layer in black color and the bottom layer in gray color): (a) Top layer illustration with unfolded upper-board and side-board; (b) Bottom layer illustration with unfolded upper-board and side-board; (c) Bottom layer of the upper-board; (d) Top layer of the side-board; (e) Bottom layer of the side-board.

The purpose of introducing the parasitic strip (c'-d'-e') is to broaden the bandwidth. After adding the parasitic strip (c'-d'-e'), an additional resonant mode is generated; the electromagnetic coupling between the monopole antenna (a-b-c) and the parasitic strip (c'-d'-e') can be controlled by the length of the gap $\left(b^{\prime}-c^{\prime}\right)$, which is formed by the $c^{\prime}-d^{\prime}$ section of the parasitic strip and the $a^{\prime}-b^{\prime}$ section printed on the bottom layer of the upper board, as shown in Figure1 (e).The higher resonance frequencies are mainly affected by the monopole antenna (a-b-c) while the lower resonance frequencies are affected by the monopole antenna $(a-b-c)$ and the parasitic strip (c'-d'-e') together.

\section{Results and Discussion}

The proposed antenna was simulated and optimized using EM software (HFSS.10) [6] and the measured results was obtained with an Agilent Network Analyzer E5071B. The simulated and measured return losses are compared in Figure 3. It can be found that the measured result agrees reasonably with the simulated result with an acceptable frequency discrepancy. The measured $-10 \mathrm{~dB}$ impedance bandwidth is $1080 \mathrm{MHz}(1920-3000 \mathrm{MHz})$, covering the UMTS $(1920-2170 \mathrm{MHz})$, telemetry frequency band $(2200-2300 \mathrm{MHz})$, WLAN $(2400-2483 \mathrm{MHz})$ and WiMAX $(2500-2690 \mathrm{MHz})$ bands. Two resonance frequencies can be observed across the operating bandwidth. The ripples at the higher frequencies are mainly generated by the feeding cable.

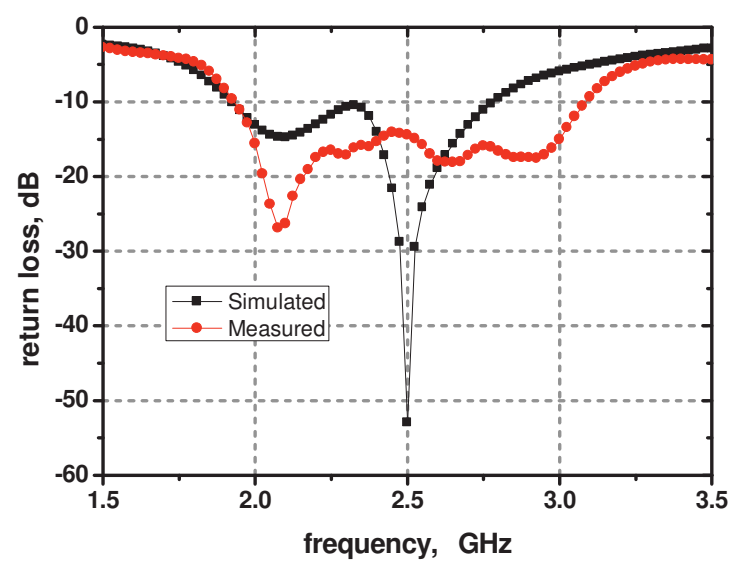

Fig. 3. Measured and simulated return losses of the proposed antenna.

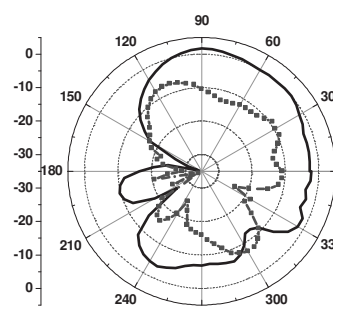

Fig. 4. Measured radiation patterns of the proposed antenna at $2.44 \mathrm{GHz}$.

The radiation characteristics of the proposed antenna were measured in an RF anechoic chamber. Figure 4 depicts the radiation patterns at $2.44 \mathrm{GHz}$. The radiation patterns show nearly omni-directional shapes in the $y$-z planes. The measured gain at $2.44 \mathrm{GHz}$ is $3.7 \mathrm{dBi}$.

\section{Conclusion}

A dual-frequency monopole antenna with a parasitic radiating strip for wireless terminals in communication and telemetry systems has been proposed. A meandered parasitic strip is used for generating dual-frequency and broadband characteristics. The measured -10 $\mathrm{dB}$ impedance bandwidth is $1080 \mathrm{MHz}(1920-$ $3000 \mathrm{MHz})$, covering the UMTS (1920$2170 \mathrm{MHz})$, telemetry frequency band(2200$2300 \mathrm{MHz}), \quad$ WLAN $(2400-2483 \mathrm{MHz})$ and WiMAX(2500-2690MHz) bands. Thus, the proposed antenna is suitable for wireless terminal in communication and telemetry systems. 


\section{References}

[1] C.R. Rowell, and R.D. Murch, A capacitively loaded PIFA for compact mobile telephone handsets, IEEE Trans. Antennas Propag 45, 837-842(1997); DOI: 10.1109/8.57563

[2] C.H. Chang, and K.L. Wong, Printed N/8-PIFA for penta-band WWAN operation in the mobile phone, IEEE Trans. Antennas Propag 57, 13731381 (2009); doi: 0.1109/TAP.2009.2016722

[3] D.M. Nashaat, H.A. Elasadek, and H. Ghaldi, Single feed compact quad-band PIFA antenna for wireless communication applications, IEEE Trans. Antennas Propag 53, 2631-2635 (2005); doi: 10.1109/TAP.2005.851872

[4] P. Ciais, R. Staraj, G. Kossiavas, and C. Luxey, Compact internal multiband antenna for mobile phone and WLAN standards, Electron Lett 40, 920-921(2004); doi:10.1049/el:20045026

[5] J.Y. Jan, and L.C. Tseng, Small planar monopole antenna with a shorted parasitic inverted- $L$ wire for wireless communications in the 2.4-, 5.2-, and 5.8-GHz bands, IEEE Trans. Antennas Propag 52, 1903-1905 (2004); doi: 10.1109/TAP.2004.831370

[6] Ansoft Corporation, Available at http://www.ansoft.com/products/hf/hfss, Ansoft Corporation HFSS. 